\title{
EFEITO DE BIOATIVADOR COM ADUBAÇÃO ORGÂNICA NO DESENVOLVIMENTO DA ALFACE AMERICANA cV. LUCY BROWN
}

Allan Remor Lopes ${ }^{1}$, Marcelo Dotto ${ }^{2}$, Carlos Rodinei de Mello ${ }^{3}$, Kelli Pirola ${ }^{4}$, Alessandro Paggiarin Zanella $^{2}$, Camila Moreno Giarola ${ }^{5}$, Acir Felipe Grolli Carvalho' ${ }^{2}$, Alvaro Rodrigo Freddo ${ }^{2}$

\begin{abstract}
RESUMO - A alface possui grande consumo nacional e mundial, e necessita de novas técnicas que otimizem sua produção. Os bioativadores são substâncias orgânicas que atuam no desenvolvimento vegetal podendo atuar nos fatores de transcrição e expressão gênica das plantas. Assim, objetivou-se verificar o efeito de bioativador associada a adubação orgânica no desenvolvimento da alface americana "Lucy Brown". Utilizou-se o delineamento experimental em blocos ao acaso, com 8 tratamentos e 4 repetições, sendo estes: (T1: Esterco bovino (EB); T2: Esterco bovino + bioativador (EBB); T3: Cama de aviário (CA); T4: Cama de aviário + bioativador (CAB); T5: Palhada (PA); T6: Palhada + bioativador (PAB); T7: Solo (SO); T8: Solo + bioativador (SOB). Foram avaliadas as seguintes características: Peso da raiz, diâmetro do caule, altura da planta, massa verde da parte aérea, massa total e número de folhas. A adição do bioativador na palhada não melhorou o desenvolvimento da alface Lucy Brown. O melhor desenvolvimento da alface Lucy Brown foi obtido pelas adubações com EBB e CAB.
\end{abstract}

Palavras chave: adubo orgânico, bioestimulante, Lactuca sativa L.

\section{EFFECT OF BIOACTIVATOR WITH ORGANIC FERTILIZATION IN THE DEVELOPMENT OF THE AMERICAN LETTUCE Cv. LUCY BROWN}

\begin{abstract}
Lettuce has great national and world consumption, and it needs new techniques that optimize its production. Bioactivators are organic substances that act on plant development and can act on the transcription factors and gene expression of plants. The objective of this study was to verify the effect of bioactivator associated with organic fertilization on the development of american lettuce "Lucy Brown". The experimental design was a randomized block design (DBC) with 8 treatments and 4 repetitions, as follows: (T1: Bovine manure (EB); T2: Bovine manure + bioactivator (EBB); T3: Poultry manure (CA); T4: Poultry maneure + bioactivator (CAB); T5: Mulching (PA); T6: Mulching + bioactivator (PAB); T7: Soil (SO); T8: Soil + bioactivator (SOB). The following characteristics were evaluated: Root weight, stem diameter, plant height, fresh shoot mass, total mass and number of leaves. The addition of bioactivator in mulching did not improve the development of Lucy Brown lettuce. The best development of Lucy Brown lettuce was obtained by fertilization with EBB and CAB.
\end{abstract}

Keywords: biostimulant, Lactuca sativa L., organic manure.

\section{INTRODUÇÃO}

No Brasil, a alface é hortaliça mais consumida e comercializada, sendo utilizada de diversas formas na culinária. Devido a esse amplo cultivo no território nacional, se torna necessário a busca por técnicas que propiciem a otimização do produto, garantindo produção e sustentabilidade ambiental nas áreas de cultivo dessa hortaliça (Moreira et al., 2014).

Dentre as técnicas que visam uma maior sustentabilidade ambiental nas áreas de cultivo das

\footnotetext{
${ }^{1}$ Professor, União de Ensino do Sudoeste do Paraná - FAED, Dois Vizinhos-PR. Contato: allanremorlopes@gmail.com

${ }^{2}$ Professor, União de Ensino do Sudoeste do Paraná - FAED, Dois Vizinhos-PR.

${ }^{3}$ Acadêmico de Agronomia, União de Ensino do Sudoeste do Paraná - FAED, Dois Vizinhos-PR.

${ }^{4}$ Doutoranda em Agronomia, Universidade Tecnológica Federal do Paraná - UTFPR, Dois Vizinhos - PR.

${ }^{5}$ Acadêmica, Universidade Paranaense - UNIPAR, Umuarama-PR.
} 
hortaliças, a adubação orgânica se destaca. A alface responde bem a adubação orgânica, devido a sua exigência por solos ricos em nutrientes (Montemurro et al., 2010).

A utilização de adubação orgânica oriunda de estercos animais e compostos orgânicos, tem sido utilizada no cultivo de hortaliças em muitas propriedades agrícolas (Ziech et al., 2014). Para Silva et al. (2010), o uso de resíduos orgânicos se torna uma opção atrativa na agricultura devido ao custo dos fertilizantes minerais e a crescente poluição ambiental. Além disso, Souza et al. (2005) relatam que o uso desordenado de fertilizantes minerais pode comprometer a qualidade final do produto e até mesmo prejudicar a saúde dos consumidores.

Os bioativadores são obtidos pela mistura de dois ou mais reguladores vegetais, com outras substâncias (aminoácidos, nutrientes, vitaminas), promovendo o equilíbrio hormonal das plantas e favorecendo a expressão do potencial genético (Silva et al., 2008).

Diversos estudos já demonstraram resultados promissores no uso de bioativadores no trigo (Pekarskas, 2012), pepino e tomate (Jankauskiene \& Surviliene, 2009), feijoeiro comum (Brito, Dequech \& Brito, 2012) e batata (Jakiene, Venskutonis \& Michevicius, 2008). No entanto, o seu uso associado a adubação orgânica no desenvolvimento da alface ainda não foi estudado.

Sendo assim, o objetivo desse trabalho foi verificar o efeito do bioativador em adubação orgânica no desenvolvimento da alface.

\section{MATERIAL E MÉTODOS}

O experimento foi realizado em uma propriedade rural no município de São João, no estado do Paraná $\left(25^{\circ} 49240^{\prime \prime} \mathrm{S}\right.$ e $\left.52^{\circ} 432313 \mathrm{~W}\right)$. Com relação ao clima, a região apresenta o clima subtropical úmido (Cfa), segundo a classificação de Köppen. O solo encontrado na propriedade rural é classificado como Latossolo vermelho distroférrico, e suas características químicas estão descritas na Tabela 1.
Quanto aos tratamentos utilizados, foram diferentes fontes de adubação orgânica, com e sem a presença do bioativador Penergetic ${ }^{\circledR}$, conforme a seguir: T1: Esterco bovino sem adição de bioativador, T2: Esterco bovino com adição do bioativador, T3: Cama de aves sem adição de bioativador, T4: Cama de aves com adição de bioativador, T5: Palhada sem adição de bioativador, T6: Palhada com adição de bioativador, T7: Solo sem adição de bioativador e T8: Solo com adição de bioativador. O delineamento utilizado foi de blocos ao acaso, com 8 tratamentos e 4 repetições.

A quantidade aplicada no solo, para cada tratamento, foi equivalente, a $40 \mathrm{tha}^{-1}$, incorporados na área total da parcela (Trani et al., 2007). Cada parcela era composta por quatro fileiras, com oito plantas, no espaçamento de $0,25 \times 0,25 \mathrm{~m}$. As sementes da cv. Lucy Brown, pertencente ao grupo Americana, foram semeadas em bandejas de isopor com 128 células usando-se substrato comercial Plantmax ${ }^{\circledR}$.

A colheita foi realizada aos $35 \mathrm{DAS}$, com as plantas cortadas rente ao solo, e em seguida, avaliou-se o peso da raiz $(\mathrm{g})$, massa fresca da parte aérea $(\mathrm{g})$ e massa total das plantas, com balança de precisão. Ainda foram analisados o diâmetro do caule $(\mathrm{cm})$, altura da planta com régua graduada e contagem manual do número de folhas por planta (SOUZA et al., 2016).

Para a realização do experimento, o uso do bioativador foi utilizado conforme a análise de solo da área experimental, e a irrigação conforme necessidade hídrica da alface.

Os resultados obtidos foram submetidos a ANOVA, e ao teste Tukey a 5\% de significância, pelo software Assistat 7.5 (ASSIS, 2008).

\section{RESULTADOS E DISCUSSÃO}

A Tabela 2 apresenta o peso da raiz (g) da alface em função de diferentes adubações orgânicas com e sem o uso de bioativador. O uso do bioativador só teve influência na adubação orgânica com cama de aves (CAB) e no solo com bioativador (SOB), quando

Tabela 1 - Análise química do solo utilizado na área experimental

\begin{tabular}{|c|c|c|c|c|c|c|c|c|c|c|}
\hline \multicolumn{11}{|c|}{ Parâmetros analisados } \\
\hline M.O. & $\mathrm{pH}$ & $\mathrm{P}$ & K & $\mathrm{Ca}$ & $\mathrm{Mg}$ & Al & $\mathrm{H}+\mathrm{Al}$ & S.B. & CTC & $\mathrm{V}$ \\
\hline $\mathrm{g} \mathrm{dm}^{-3}$ & & & $\mathrm{mg} \mathrm{dn}$ & & & $\mathrm{Cmc}$ & & & $\%$ & \\
\hline 62,99 & 5,40 & 60,36 & 1,20 & 8,31 & 3,49 & 0 & 5,02 & 13,00 & 18,02 & 72,14 \\
\hline
\end{tabular}


comparado com as mesmas fontes de adubação sem bioativador, sendo que a $\mathrm{CAB}$ apresentou o maior peso da raiz $(11,95 \mathrm{~g})$ entre todas as adubações.

O diâmetro do caule $(\mathrm{cm})$ para as diferentes adubações orgânicas com e sem bioativador está apresentado na Tabela 3. O esterco bovino com bioativador (EBB) e solo com bioativador (SOB), foram os únicos tratamentos em que o bioativador teve diferença quando comparado com os mesmos sem bioativador. Além disso, os mesmos (EBB e SOB) juntamente com cama de aves com bioativador (CAB), foram os tratamentos com maior diâmetro do caule, com $8,88 \mathrm{~cm}, 8,54$ e $8,92 \mathrm{~cm}$, respectivamente. Viana \& Vasconcelos (2008) identificaram aumento de produtividade da alface ao utilizarem esterco bovino e cama de aves.

Para a altura da planta, apenas o EBB foi eficaz e aumentou sua altura, quando comparado com o esterco bovino (EB). Nos demais tratamentos, a adição do bioativador não proporcionou alterações na altura da planta (Tabela 4). Todos os resultados da altura da planta das adubações orgânicas estudadas se mostraram superiores a diferentes doses de superfosfato triplo (Kano, Cardoso \& Villas Boas, 2012).

Em relação ao peso da parte aérea (Tabela 5), observa-se que o apenas na adubação com palhada o bioativador não aumentou seu peso da parte aérea. As adubações EBB e CAB obtiveram o maior peso da parte aérea com 253,66 e 281,50 g respectivamente.

Assim como na massa verde da parte aérea (Tabela 6), as adubações com EBB e CAB obtiveram a maior massa total (Tabela 5), com 265,71 e 295,00 g, respectivamente.

Tabela 2 - Peso da raiz (g) da alface, em função de diferentes adubações orgânicas com e sem adição de bioativador

\begin{tabular}{lc}
\hline \multicolumn{1}{c}{ Tratamentos } & Peso de raiz $(\mathrm{g})$ \\
\hline EB - Esterco bovino & $8,94^{\mathrm{b}}$ \\
EBB - Esterco Bovino + bioativador & $9,73^{\mathrm{ab}}$ \\
CA - Cama de aves & $8,09^{\mathrm{b}}$ \\
CAB - Cama de aves + bioativador & $11,95^{\mathrm{a}}$ \\
PA - Palhada & $7,91^{\mathrm{b}}$ \\
PAB - Palhada + bioativador & $7,83^{\mathrm{bc}}$ \\
SO - Solo & $5,62^{\mathrm{c}}$ \\
SOB - Solo + bioativador & $8,24^{\mathrm{b}}$ \\
\hline
\end{tabular}

*Médias seguidas da mesma letra na coluna não diferem entre si, a $5 \%$, pelo teste de Tukey.
Tabela 3 - Diâmetro do caule $(\mathrm{cm})$ da alface, em função de diferentes adubações orgânicas com e sem adição de bioativador

\begin{tabular}{lc}
\hline Tratamentos & $\begin{array}{c}\text { Diâmetro do } \\
\text { caule }(\mathrm{cm})\end{array}$ \\
\hline EB - Esterco bovino & $7,54^{\mathrm{b}}$ \\
EBB - Esterco bovino + bioativador & $8,88^{\mathrm{a}}$ \\
CA - Cama de aves & $8,33^{\mathrm{ab}}$ \\
CAB - Cama de aves + bioativador & $8,92^{\mathrm{a}}$ \\
PA - Palhada & $7,54^{\mathrm{b}}$ \\
PAB - Palhada + bioativador & $7,59^{\mathrm{b}}$ \\
SO - Solo & $6,14^{\mathrm{c}}$ \\
SOB - Solo + bioativador & $8,54^{\mathrm{ab}}$ \\
\hline
\end{tabular}

*Médias seguidas da mesma letra na coluna não diferem entre si, a $5 \%$, pelo teste de Tukey.

Tabela 4 - Altura da planta $(\mathrm{cm})$ da alface, em função de diferentes adubações orgânicas com e sem adição de bioativador

\begin{tabular}{lc}
\hline Tratamentos & $\begin{array}{c}\text { Altura da } \\
\text { planta }(\mathrm{cm})\end{array}$ \\
\hline EB - Esterco bovino & $30,79^{\mathrm{b}}$ \\
EBB - Esterco bovino + bioativador & $36,83^{\mathrm{a}}$ \\
CA - Cama de aves & $32,25^{\mathrm{ab}}$ \\
CAB - Cama de aves + bioativador & $32,87^{\mathrm{ab}}$ \\
PA - Palhada & $30,62^{\mathrm{b}}$ \\
PAB - Palhada + bioativador & $31,56^{\mathrm{ab}}$ \\
SO - Solo & $28,58^{\mathrm{b}}$ \\
SOB - Solo + bioativador & $32,54^{\mathrm{ab}}$ \\
\hline
\end{tabular}

*Médias seguidas da mesma letra na coluna não diferem entre si, a $5 \%$, pelo teste de Tukey.

Tabela 5 - Massa verde da parte aérea (g) da alface, em função de diferentes adubações orgânicas com e sem adição de bioativador

\begin{tabular}{lc}
\hline Tratamentos & $\begin{array}{c}\text { Peso da parte } \\
\text { aérea }(\mathrm{g})\end{array}$ \\
\hline EB - Esterco bovino & $191,74^{\mathrm{de}}$ \\
EBB - Esterco bovino + bioativador & $253,66^{\mathrm{ab}}$ \\
CA - Cama de aves & $227,76^{\mathrm{bc}}$ \\
CAB - Cama de aves + bioativador & $281,50^{\mathrm{a}}$ \\
PA - Palhada & $210,41^{\mathrm{cd}}$ \\
PAB - Palhada + bioativador & $233,24^{\mathrm{bc}}$ \\
SO - Solo & $178,91^{\mathrm{e}}$ \\
SOB - Solo + bioativador & $209,08^{\mathrm{cd}}$ \\
\hline
\end{tabular}

* Médias seguidas da mesma letra na coluna não diferem entre si, a $5 \%$, pelo teste de Tukey. 
O número de folhas foi igual para todas as adubações com bioativador, com uma média de 22 a 24 folhas (Tabela 7). Batista et al. (2012) obtiveram uma média de 24,1 folhas de alface por planta com a utilização de esterco bovino como fonte de adubação. Andrade Júnior et al. (2005) relatam médias de 22 a 27 folhas para a alface tipo lisa cvs. Elisa e Regina, ao utilizarem materiais orgânicos.

O uso do bioativador associado as diferentes adubações orgânicas mostrou-se viável para algumas fontes de adubação e alguns parâmetros de desenvolvimento da alface (Tabelas 1 a 7).

\section{CONCLUSÕES}

O esterco bovino com bioativador (EBB) e a cama de aves com bioativador (CAB) apresentaram o melhor desenvolvimento em todos os parâmetros analisados.

Tabela 6 - Massa total (g) da alface, em função de diferentes adubações orgânicas com e sem adição de bioativador

\begin{tabular}{lc}
\hline Tratamentos & Peso total \\
\hline EB - Esterco bovino & $204,58^{\mathrm{de}}$ \\
EBB - Esterco bovino + bioativador & $265,71^{\mathrm{ab}}$ \\
CA - Cama de aves & $249,08^{\mathrm{bc}}$ \\
CAB - Cama de aves + bioativador & $295,00^{\mathrm{a}}$ \\
PA - Palhada & $219,37^{\mathrm{cd}}$ \\
PAB - Palhada + bioativador & $243,73^{\mathrm{bc}}$ \\
SO - Solo & $186,22^{\mathrm{e}}$ \\
SOB - Solo + bioativador & $218,58^{\mathrm{cd}}$ \\
\hline
\end{tabular}

*Médias seguidas da mesma letra na coluna não diferem entre si, a $5 \%$, pelo teste de Tukey.

Tabela 7 - Número de folhas da alface, em função de diferentes adubações orgânicas com e sem adição de bioativador

\begin{tabular}{lc}
\hline Tratamentos & $\begin{array}{c}\text { Número } \\
\text { de folhas }\end{array}$ \\
\hline EB - Esterco bovino & $21,50^{\mathrm{bc}}$ \\
EBB - Esterco bovino + bioativador & $24,50^{\mathrm{a}}$ \\
CA - Cama de aves & $23,58^{\mathrm{ab}}$ \\
CAB - Cama de aves + biotivador & $24,50^{\mathrm{a}}$ \\
PA - Palhada & $22,04^{\mathrm{abc}}$ \\
PAB - Palhada + bioativador & $22,24^{\mathrm{abc}}$ \\
SO - Solo & $19,66^{\mathrm{c}}$ \\
SOB - Solo + bioativador & $23,33^{\mathrm{ab}}$ \\
\hline
\end{tabular}

* Médias seguidas da mesma letra na coluna não diferem entre si, a $5 \%$, pelo teste de Tukey.
O uso do bioativador na palhada (PAB) não melhorou o desenvolvimento da alface quando comparado a palhada sem o bioativador (PA).

\section{LITERATURA CITADA}

ANDRADE JÚNIOR, V. C.; YURI, J. E.; NUNES, U. R. et al. Emprego de tipos de cobertura de canteiro no cultivo da alface. Horticultura Brasileira, v. 23, p. 899-903, 2005.

ASSIS, F. Assistat 7.5. Departamento de Engenharia Agrícola, UFCG. Disponível em: $<$ http://www.assistat.com $>$.

BATISTA, M. A. V.; VIEIRA, L. A.; SOUZA, J. P. et al. Efeito de diferentes fontes de adubação sobre a produção de alface no município de Iguatu-CE. Revista Caatinga, v. 25, n. 3, p. 8-11, 2012.

BRITO, R. O.; DEQUECH, F. K.; BRITO, R. M. Use of penergetic products $\mathrm{P}$ and $\mathrm{K}$ in the snap bean production. Annual Report of the Bean Improvement Cooperative, v. 55, p. 277-278, 2012.

JAKIENE, E.; VENSKUTONIS, V.; MICHEVICIUS, $\mathrm{V}$. The effect of the additional fertilization with liquid complex fertilizers and growth regulators on potato productivity. Sodininkyste ir Darzininkyste, v. 27, n. 2, p. 259-267, 2008.

JANKAUSKIENE, J.; SURVILIENE, E. Influence of growth regulator on seed germination energy and biometrical parameter of vegetables.

Sodininkyste ir Darzininkyste, v. 28, n. 3, p. 69$77,2009$.

KANO, C.; CARDOSO, A. I. I.; VILLAS BOAS, R. L. Acúmulo de nutrientes e resposta da alface à adubação fosfatada. Biotemas, v. 25, n. 3, p. 39 47, 2012.

MONTEMURRO, F.; FERRI, D.; TITTARELLI, F. et al. Anaerobic digestate and on-farm compost application: Effects on lettuce (Lactuta sativa L.) crop production and soil properties. Compost Science and Utilization, v.18, p. 184-193, 2010.

MOREIRA, M.; SANTOS, C.; LUCAS, A. et al. Lettuce production according to different sources of organic matter and soil cover. Agricultural Science, v. 5, p. 99-105, 2014. 
PEKARSKAS, J. Effect of growth activator Penergetic-P on organically grown spring wheat. Zemes Ukio Mokslai, v. 19, n. 3, p. 151-160, 2012.

SILVA, F. A. M.; VILAS-BOAS, R. L.; SILVA, R. B. da. Resposta da alface à adubação nitrogenada com diferentes compostos orgânicos em dois ciclos sucessivos. Acta Scientiarum Agronomy, v. 32, p. 131-137, 2010.

SILVA, T. T. A.; PINHO, E. V. R. V.; CARDOSO, D. L. et al. Qualidade fisiológica de sementes de milho na presença de bioestimulantes. Ciência $e$ Agrotecnologia, v. 32, n. 3, p. 840-846, 2008.

SOUZA, A. A. L.; MOREIRA, F. J. C.; ARAÚJO, B. A.; LOPES, F. G. N.; SILVA, M. E. S.; CARVALHO, B. S. Desenvolvimento inicial de duas variedades de alface em função de dois tipos de substratos e cobertura do solo. Revista Brasileira de Engenharia de Biossistemas, v. 10, n. 3, p. 316-326, 2016.
SOUZA, P. A.; NEGREIROS, M. Z.; MENEZES, J. B. et al. Características químicas de alface cultivada sob efeito residual da adubação com composto orgânico. Horticultura Brasileira, v. 23, p. 754-757, 2005.

VIANA, E. M.; VASCONCELOS, A. C. F. Produção de alface adubada com termofosfato e adubos orgânicos. Revista Ciência Agronômica, v. 39, n. 2, p. 217-224, 2008.

ZIECH, A. R. D.; CONCEIÇÃO, P. C.; LUCHESE, A. V. et al. Cultivo de alface em diferentes manejos de cobertura do solo e fontes de adubação. Revista Brasileira de Engenharia Agrícola e Ambiental, v. 18, n. 9, p. 948-954, 2014.

Recebido para publicação em 11/04/2019 e aprovado em 28/06/2019. 